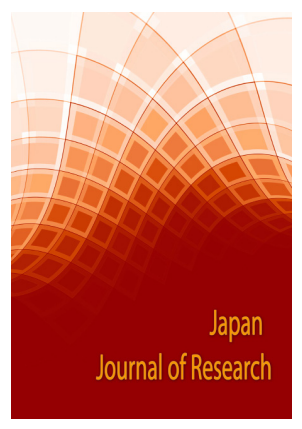

Correspondence

Tiiu Kullisaar

Department of Biochemistry, Institute of Biomedicine and Translational Medicine, Faculty of Medicine, University of Tartu, 19 Ravila Street, 50411, Tartu, Estonia

- Received Date: 07 July 2020;

- Accepted Date: 17 July 2020;

- Publication Date: 09 August 2020.

Copyright

(c) 2020 Science Excel. This is an openaccess article distributed under the terms of the Creative Commons Attribution 4.0 International license.

\title{
Lactobacillus fermentum ME-3 - a probiotic with potential for anti-atherogenic, anti-oxidative and anti-diabetic application
}

\author{
Tiiu Kullisaar ${ }^{1 *}$, Aune Rehema ${ }^{1}$, Marc Fremont ${ }^{2}$ and Mihkel Zilmer ${ }^{1}$ \\ ${ }^{1}$ Department of Biochemistry, Institute of Biomedicine and Translational Medicine, Faculty of Medicine, University of Tartu, 19 \\ Ravila Street, 50411, Tartu, Estonia \\ ${ }^{2}$ Marc Fremont, VF Biosciense SAS, Executive/R\&R Director, 310 Rue Jules Valles, 59120 Loos-lez-Lille, France
}

Lactobacilli are normal inhabitants of human microbiota. Recent excellent review focused on huge practical potential of Lactobacillus fermentum, Lf ME-3 [1]. Especially valuable is information about the $L f$ strains that have in addition to common properties also the strainspecific beneficial effects on the host. A number of studies (in vitro, clinical randomized trials, clinical randomized double blind trials) have highlighted that human origin Lactobacillus fermentum ME-3 (DSM14241, LfME-3) has several specific properties including antiatherogenic and anti-oxidative effects, possible anti-diabetic influence, ability to manage multiple protective systems like superoxide dismutase, glutathione system, etc [2-4]. For example, probiotic $L f \mathrm{ME}-3$ has two special enzymes needed for the redox cycle of glutathione (glutathione peroxidase and glutathione reductase) confirmed by the immunohistochemical method [5]. Beside that $L f$ ME-3 has glutamyl cystein ligase genes and glycine transporters (MiSeq, Illumina) both are needed to operate glutathione system and glutathione recycling. In addition, use of the Lf ME-3-fermented kefir for 14 days to 43 human subjects results in increase of the peak at $\mathrm{m} / \mathrm{z} 308$ (corresponding to glutathione) in the serum established by using MALDI-TOF mass spectrometer [6].

Recently we carried out the metabolomics study about effects of special LfME-3 containing supplement (Reg'Activ cholesterol ${ }^{\mathrm{TM}}$ [7] with Absolute IDQ p180 Kit (BIOCRATES Life Science AG, Innsbruck, Austria) do to targeted metabolomics approach using an ultra-performance liquid chromatography (UPLC)/MS/MS system (Acquity UPLC [Waters] TQ-S triple quadrupole MS/MS [Waters]) We measured up to 180 endogenous metabolites from various classes including acylcarnitines, amino acids, biogenic amines, glycerophospholipids and sphingolipids. After 8 weeks of supplementation a remarkable number of metabolites expressed statistically significant changes. After implementation more stronger data analysis approach the changes of long-chain acylcarnites (C16, C18), phosphatidylcholines (PCaa C36:3; PCaa C38:3; PCaa C40:5; PCae $\mathrm{C} 42: 3)$, sphingomyelines $(\mathrm{SM}(\mathrm{OH}) \mathrm{C} 22: 1 ; \mathrm{SM}(\mathrm{OH})$ C22:2; SM C24:0) and an OxS marker (a decli $\neg$ ne of $\mathrm{Me}-\mathrm{SO} / \mathrm{Met}$ ) remain statistically significant $(\mathrm{P}=0.02 \ldots 0.00005)$. According to a number of literature data, all established metabolite shifts speak to favor of decline of OxS and inflammation level and antidiabetic influence.

\section{Conflict of interests}

Authors have no conflict of interest to declare.

\section{References}

1. Naghmouchi K, Belguesmia Y, Bendali F, Spano G, Seal BS, Drider D. Lactobacillus fermentum: a bacterial species with potential for food preservation and biomedical applications. Crit Rev Food Sci Nutr. 2019;1-13.

2. Kullisaar T, Zilmer M, Mikelsaar M, et al. Two antioxidative lactobacilli strains as promising probiotics. Int J Food Microbiol. 2002;72(3):215224.

3. Kullisaar T, Songisepp E, Mikelsaar M, Zilmer K, Vihalemm T, Zilmer M. Antioxidative probiotic fermented goats' milk decreases oxidative stressmediated atherogenicity in human subjects. Br J Nutr. 2003;90(2):449-456.

4. Kullisaar T, Shepetova J, Zilmer K, et al., An antioxidant probiotic reduces postprandial lipemia and oxidative stress. Centr Eur J Biol. 2011;6:32-40.

5. Kullisaar T, Songisepp E, Aunapuu M, et al. Complete glutathione system in probiotic Lactobacillus fermentum ME-3. Prikl Biokhim Mikrobiol. 2010;46(5):527-531.

6. Rehema A, Kullisaar K, Seer K, Reinmann K, Zilmer M, Kilk K. Proteomic proof that a probiotic elevates glutathione level in human seerum. Life Science. 2015;10:217-224.

7. Kullisaar T, Zilmer K, Salum T, Rehema A, Zilmer M. The Use of Probiotic L.fermentum ME-3 Containing Reg'Activ Cholesterol Supplement for 4 Weeks Has a Positive Influence on Blood Lipoprotein Profiles and Inflammatory Cytokines: An Open-Label Preliminary Study. Nutr J. 2016;15(1):93.
Citation: Kullisaar T, et al. Lactobacillus fermentum ME-3 - a probiotic with potential for antiatherogenic, anti-oxidative and anti-diabetic application. Japan J Res. 2020;1(2):1-2. 